\title{
Persistent neonatal hyperbilirubinemia resulting from Gilbert's syndrome in association with RhD hemolytic disease
}

\author{
Fernando P. Facchini, ${ }^{1}$ Angela Maria de Assis ${ }^{2}$
}

\begin{abstract}
Objective: To report on an infrequent association of pathologies causing considerable increase in bilirubin production and a signifiant decrease in its excretion.

Description: The third pregnancy of an RhD negative woman. Her first child was normal and delivered to term and did not receive Rhogam. The second pregnancy was problematic due to Rh isoimmunization. She delivered a child to term, who required three exchange transfusions, but died on the 8th day of life. The third child was delivered at term, ORh positive, direct Coombs positive and had stump bilirubin of $6.5 \mathrm{mg} / \mathrm{dl}$ and hematocrit at $44 \%$. Five hours after birth the child was jaundiced. Phenobarbital and intensive phototherapy were introduced. Hyperbilirubinemia was soon controlled, but relapsed whenever phototherapy was discontinued. On the 10th day of life the child received a transfusion for significant anemia. As jaundice persisted to the 13th day, associated Gilbert syndrome was considered and DNA sequence analysis was requested. The test demonstrated a mutant homozygote genotype UDPT1A1 $[T A]_{7}$ TAA. Phototherapy remained necessary until the 17 th day of life and she was discharged from hospital the following day, after bilirubinemia had been controlled. She returned for follow-up and exhibited normal growth and neurological development.

Comments: This case demonstrates the significance of increased bilirubin production/decreased bilirubin excretion causing intense hyperbilirubinemias and, in the abnsence of vigorous treatment, kernicterus. The effectiveness of intense phototherapy has also been demonstrated, reducing the risks of more aggressive treatments such as exchange transfusion. It also provides evidence of the importance of bilirubinemia follow-up until complete resolution.
\end{abstract}

J Pediatr (Rio J). 2005;81(5):421-4: Neonatal jaundice, hyperbilirubinemia, Gilbert's syndrome, intensive phototherapy.

\section{Introduction}

Gilbert's syndrome was described at the start of the twentieth century. ${ }^{1}$ Its principal characteristic was the appearance of chronically recurrent, discrete indirect hyperbilirubinemia. This pathology affects approximately 5 to $10 \%{ }^{2}$ of the population and has been described most

1. PhD. Retired professor, Department of Pediatrics, Faculdade de Ciências Médicas (FCM), Universidade Estadual de Campinas (UNICAMP), Campinas, SP, Brazil.

2. MSc. FCM, UNICAMP, Campinas, SP, Brazil.

This study was carried out at the Neonatology Division of CAISM and Laboratory of Hemoglobin and Genoma at FCM/UNICAMP.

Manuscript received May 11 2005, accepted for publication Aug 102005.

Suggested citation: Facchini FP, de Assis AM. Persistent neonatal hyperbilirubinemia resulting from Gilbert's syndrome in association with RhD hemolytic disease. J Pediatr (Rio J). 2005;81:421-4. frequently in young adults, normally associated with periods of fasting during intercurrent conditions. The genetic basis of the disease was described 10 years ago. ${ }^{2}$ A variant of the promoter for the gene that codes UDP-glucuronosyltransferase 1 (UDPGT1) is thought to be responsible for the reduction in bilirubin glucuronides, a deficiency of which causes the syndrome. The transcription (RNA messenger) contains an additional TA base at the TATAA promoter region which originates at $7\left(\mathrm{~A}[\mathrm{TA}]_{7} \mathrm{TAA}\right)$ instead of the normal $6\left(\mathrm{~A}[\mathrm{TA}]_{6} \mathrm{TAA}\right)$. This discovery triggered interest in its repercussions for neonatal jaundice, and its involvement was confirmed. 3,4 This transcription was recently renamed UGT $1 \mathrm{~A} 1 * 28^{5}$ and reduces hepatic glucuronic acid conjugation by about $80 \%$ in homozygotes. These individuals also exhibit a small increase in bilirubin levels, responsible for discretely increased levels of total bilirubinemia. ${ }^{6}$ These levels are 
not responsible for significant hyperbilirrubinemia (>15 mg/dl) unless they are associated with conditions that cause significant increases in bilirubin production. If a glucose 6 phosphate dehydrogenase (G6PD) deficiency is concomitant, ${ }^{7}$ severe hyperbilirrubinemia and kernicterus can result. When there is a deficiency of this enzyme, but no association with Gilbert syndrome, significant hyperbilirrubinemia ( $>15 \mathrm{mg} / \mathrm{dl}$ ) is rare $(9.7 \%)$. However, among heterozygotes for Gilbert syndrome this figure increases to $31.6 \%$ and in homozygotes to $50 \%$. An association with $B$-thalassemia has also been proven. ${ }^{8,9}$ This case history attracts attention because of the association between RhD hemolytic disease with prolonged jaundice, which, while uncommon, is highly significant because it provokes intense and recurrent hyperbilirrubinemia which, if not suitably treated, leads to kernicterus.

\section{Case history}

Maternal background: Thirty-four years old, married, $\mathrm{G}_{3} \mathrm{P}_{2} \mathrm{~A}_{0}$. The first pregnancy was delivered by caesarian because of placenta previa. Gave birth to a male infant, weighing 3,650 g who progressed with no problems and did not receive Rhogam in postpartum. The second pregnancy was complicated by isoimmunization by Rh factor. A male infant was born weighing 3,750 g, anemic and jaundiced. After three exchange transfusions he died at eight days. The mother did not mention if the death was a result of the disease itself or a result of complications of the treatment.

\section{Current pregnancy}

The mother attended eight consultations from the fourth month of pregnancy onwards at the Specialized Prenatal Center at CAISM. The estimated delivery date was to be $21 / 03 / 04$. Her blood group was confirmed as $\mathrm{Rh}$ negative and indirect Coombs detected anti RhD antibodies with titers of $1: 256$. Ultrasound performed at approximately 28 weeks' pregnancy found signs of fetal anemia on Doppler evaluation. Three days later cordocentesis was performed and fetal blood groups determined (ORh + direct Coombs + ). Intrauterine transfusion was initiated, but was suspended after the administration of just $5 \mathrm{ml}$ of concentrated erythrocytes, since fetal hemoglobin was reading $12 \mathrm{~g} / \mathrm{dl}$. Ultrasound performed at 27, 29 and 30 weeks' pregnancy did not show anemia or centralized circulation on Doppler. Serological tests revealed antibodies for rubella and toxoplasmosis. The VDRL tests for HIV and hepatitis B were negative. Phenobarbital ${ }^{10}$ and corticoid were given at the end of the pregnancy.

\section{Labor and delivery}

Labor began spontaneously. A repeat caesarian was performed with epidural anesthesia. Birth took place at $14: 14$ hours on $02 / 03 / 04$. A female baby was born weighing $3,155 \mathrm{~g}$, measuring $50.5 \mathrm{~cm}$, with a head circumference of $34.5 \mathrm{~cm}, \mathrm{O} \mathrm{Rh}+$, direct Coombs,+ 39 weeks' Capurro and Apgars of 8 and 10. The clinical examination did not find jaundice or gross abnormalities. The infant was classified as born full term and appropriate for gestational age. Total bilirubin in cord blood was $6.5 \mathrm{mg} / \mathrm{dl}$ and hematocrit was $44 \%$.

\section{Clinical progress}

After 5 hours of life jaundice was already evident and phenobarbital was started at $10 \mathrm{mg} /$ day $/ 3$ days ${ }^{10}$ plus double intensive phototherapy with 14 special blue light bulbs (Philips 20W/T52), seven placed $35 \mathrm{~cm}$ above and seven $10 \mathrm{~cm}$ below the acrylic cot, with total mean irradiation of $45 \mu \mathrm{W} / \mathrm{cm}^{2} / \mathrm{nm}$, the sum of upper and lower means, measured with an MD 620-Fanem radiometer. Total bilirubinemia, assayed by direct plasma spectrophotometry, responded to phototherapy satisfactorily, but relapsed when this was suspended. The progress of bilirubins and phototherapy can best be followed in Figure 1. At 13 days of life, since the infant still exhibited significant bilirubinemia and was phototherapy dependent, DNA sequencing was performed to test for Gilbert syndrome. On the 10th day of life hematocrit had dropped to $25 \%$ and so transfusion with $75 \mathrm{ml}$ of concentrated erythrocytes was performed. Posttransfusion hematocrit was $44 \%$. As the infant was still photodependent on day 15 postpartum, phenobarbital administration was started at $5 \mathrm{mg} / \mathrm{kg} /$ day and she was transferred to a single phototherapy bed, with seven special blue lamps, intending to return her to her home town. The response was most satisfactory and 2 days later phototherapy was suspended, with no relapse during the succeeding 24 hours. She was discharged from hospital and referred for subsequent outpatients follow-up. Four days after discharge she was seen at a clinic in her home town with hematocrit at $20 \%$. At the time total bilirubin was also assayed, returning $3.4 \mathrm{mg} / \mathrm{dl}$. A transfusion was given and hematocrit rose to $32 \%$. She returned to our clinic aged 41 days, having gained $44 \mathrm{~g}$ per day, in excellent general health with normal neurological and Denver development tests for her age. Total bilirubin $(1.2 \mathrm{mg} / \mathrm{dl})$, hematocrit $(23 \%)$ and reticulocytes $(1.72 \%)$ were assayed. Audiometry did not reveal alterations. We received the result of the DNA sequencing confirming our diagnostic hypothesis of Gilbert syndrome (the genotype found was the $7 / 7$ homozygous mutant UDPT1A1 $\left.[\mathrm{TA}]_{7} \mathrm{TAA}\right)$. At 3 months and a half her hematocrit was $34 \%$, total bilirubin $0.8 \mathrm{mg} / \mathrm{dl}$ and serum ferritin $109.7 \mathrm{ng} / \mathrm{ml}$. At the last visit to our clinic, aged eight and a half months, she weighed $10,190 \mathrm{~g}$, was in excellent general condition and had normal color and neurodevelopment.

\section{Discussion}

Even pathologies that cause discrete increases of bilirubin can lead to major hyperbilirrubinemia, with kernicterus and even death if associated with Gilbert's syndrome. The association of Gilbert's syndrome and a pathology that causes large scale bilirubin production, such as sensitization to $\mathrm{RhD}$ factor, adds even greater difficulty to managing the problem. The background to the case presented here 


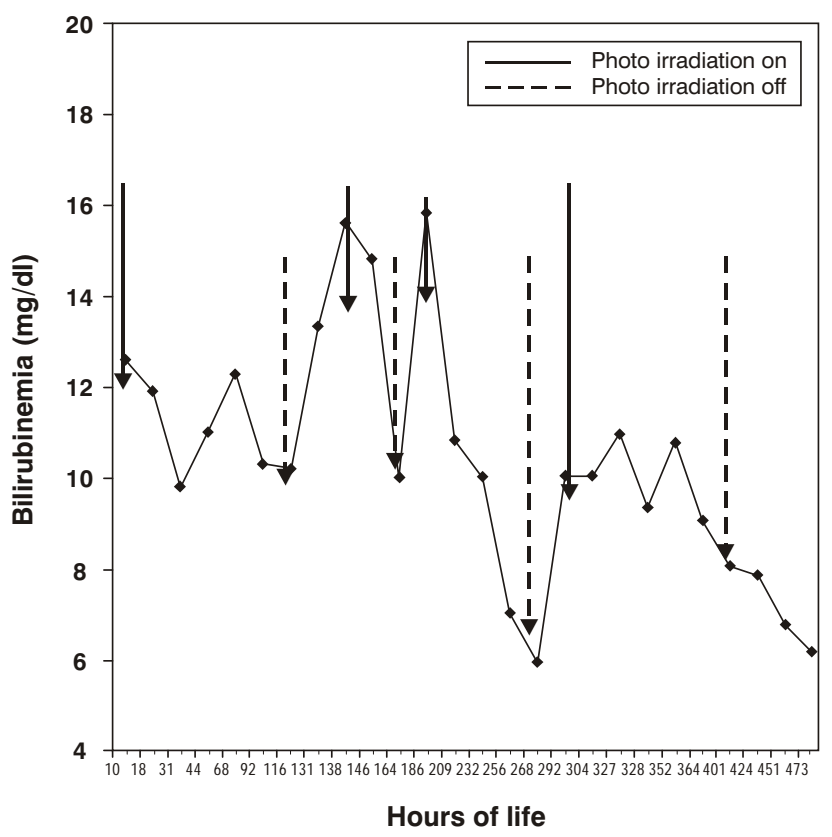

Figure 1 - Progress of bilirubins during hospital stay

confirm this progression, since the previous pregnancy had resulted in a severely jaundiced infant who died after three exchange transfusions, probably either as a result of treatment complications or of kernicterus. We would like to stress the importance of the employment of intensive phototherapy ( $>45 \mu \mathrm{W} / \mathrm{cm}^{2} / \mathrm{nm}$ ), which was effective at controlling bilirubinemia levels and avoided exchange transfusions that are comparatively higher risk. ${ }^{11,12}$ It is of interest to note that although phototherapy was able to rapidly reduce bilirubinemia levels, its suspension led to their rapidly rising once more. This condition continued until the UDP glucuronosyltransferase activity was able to better conjugate with the bilirubin formed, maintaining it at lowrisk levels. This behavior is explicable since, since these individuals are only able to attain $30 \%$ of normal glucuronization capacity, ${ }^{13-15}$ sufficient activity to reduce bilirubinemia to sub-jaundice levels is slow to appear. The severity of the hemolytic process can be evaluated by hematocrit levels of $25 \%$ aged 10 days and then $20 \%$ aged 20 days. This anemia was dealt with by two transfusions of concentrated red blood cells, the risk of which is incomparably lower than with exchange transfusion. The significant glucuronization response to phenobarbital, confirms earlier results from its use with Gilbert's syndrome ${ }^{13}$ during the neonatal period.

Once a carrier of Gilbert's syndrome has been identified, since this is a genetically transmitted disease, family members should be warned of the chance of serious jaundice in future siblings and descendents, affording to other pregnancies the chance of counseling and observation at maternity units with the necessary resources. It is worth remembering that approximately $50 \%$ of the population has at least one allele of the Gilbert syndrome promoter. ${ }^{15}$ Furthermore, lost time and wasted financial resources can be avoided investigating liver diseases in the event of the small outbreaks of jaundice that occur among these individuals when subjected to food privation. Carriers should also be warned of the increased occurrence of cholelithiasis (gallstones). ${ }^{9}$

The principal lesson to be learnt from this case is that large reductions in bilirubinemia levels after intensive phototherapy or exchange transfusion should not encourage hospital discharge without observing bilirubinemia levels for several days after withdrawing these therapeutic measures. As we were able to observe in this case, the association of Gilbert syndrome with pathologies that exhibit increased bilirubin production, dangerous levels of bilirubinemia can endure for several weeks, and require suitable observation and treatment. 14,15

\section{References}

1. Gilbert A, Lereboullet P. La cholemie simple familiale. Semaine Medicine. 1901;21:241-3.

2. Bosma PJ, Chowdhury JR, Bakker C, Gantla S, de Boer A, Oostra $B A$, et al. The genetic basis of the reduced expression of bilirubin UDP-Glucuronosiltransferase 1 in Gilbert's syndrome. N Engl J Med. 1995;333:1171-5.

3. Bancroft JD, Kreamer B, Gourley GR. Gilbert syndrome accelerates development of neonatal jaundice. J Pediatr. 1998;132:656-60. 
4. Roy-Chowdhury N, Deocharan B, Bejjanki HR, Gantla S, RoyChowdhury J, Koliopoulos C, et al. The presence of a Gilberttype promoter abnormality increases the level of neonatal hyperbilirubinemia. Hepatology. 1997;26:370A.

5. Bosma PJ. Inherited disorders of bilirubin metabolism. J Hepatol. 2003;38:107-17.

6. Kaplan M, Hammerman C, Rubaltelli FF, Vilei MT, Levy-Lahad E, Renbaum $P$, et al. Hemolysis and bilirubin conjugation in association with UDP-glucuronosyltransferase $1^{\mathrm{A}} 1$ promoter polymorphism. Hepatology. 2002;35:905-11.

7. Kaplan M, Renbaum, Levy-lahad E, Hammerman C, Lahad A, Beutler E. Gilbert syndrome and glucose 6 phosphate dehydrogenase deficiency: a dose-dependent genetic interaction crucial to neonatal hyperbilirubinemia. Proc Nat Acad Sci USA. 1997; $94: 12128-32$.

8. Sampietro M, Lupica L, Perrero L, Comino A, Di Montemuros FM, Capellini MD, et al. The expression of uridine diphosphate glucuronosyltransferase gene is a major determinant of bilirubin level in heterozygous beta-thalassemia and in glucose-6phosphate dehydrogenase deficiency. $\mathrm{Br}$ J Haematol. 1997;99:437-39.

9. Galanello R, Piras S, Barella S, Leoni GB, Cipollina L, Perseu L, et al. A cholelitiasis and Gilbert's syndrome in homozygous Bthalassemia. Br J Haematol. 2001;115:926-8.

10. Valaes TN, Harvey-Wilkes K. Pharmacologic approaches to the prevention and treatment of neonatal hyperbilirubinemia. Clin Perinatol. 1990;17:245-73.
11. Facchini FP, Bianchi MO, Brasileiro Silva BA. Fototerapia no tratamento de caso grave de doença hemolítica do recémnascido. J Pediatr (Rio J).2000;76:387-90.

12. Jackson JC. Adverse events associated with exchange transfusion in healthy and ill newborns. Pediatrics [serial on line] 1997 May [cited 2001 Feb 21];99(5). Available at: http//www.pediatr.org/ cgi/content/full/99/5/e7.

13. Roy-Chowdhury J, Roy-Chowdhury N. Unveiling the mysteries of inherited disorders of bilirubin glucuronidation. Gastroenterology. 1993;105:288-93.

14. Laforgia N, Faienza MF, Rinaldi A, D'Amato G, Rinaldi G, Iolascon A. Neonatal hyperbilirubinemia and Gilbert's syndrome. J Perinat Med. 2002;30:166-9.

15. Watchco JF, Daood MJ, Biniwale M. Understanding neonatal hyperbilirubinemia in the era of genomics. Semin Neonatol. 2002; 7:143-52.

Correspondence:

Fernando Perazzini Facchini

Rua Coronel Quirino, 910/101

CEP 13025-900 - Campinas, SP, Brazil

Tel.: + 55 (19) 3251.4735/3788.9344

Fax: +55 (19) 3788.9307

E-mail: fepefaca@fcm.unicamp.br 